\title{
Cultural and demic diffusion of first farmers, herders, and their innovations across Eurasia
}

\author{
Carsten Lemmen \\ C. L. Science Consult; Helmholtz-Zentrum Geesthacht, Lüneburg, Geesthacht, DE \\ science@carsten-lemmen.de
}

\begin{abstract}
Was the spread of agro-pastoralism from the Eurasian founder regions dominated by demic or by cultural diffusion? This study employs simulations that unfold a complex inter-regional and time varying pattern of demic and diffusive exchange processes during the Neolithisation, and thus supports from a modelling perspective the hypothesis that there is no simple or exclusive demic or cultural diffusion, but that in most regions of Eurasia a combination of demic and cultural processes were important.
\end{abstract}

IZVLEČEK - Je bila pri širitvi kmetijstva iz evrazijskih jedrnih območij pomembnejša demska ali morda kulturna difuzija? V študiji uporabimo simulacijo, ki proces neolitizacije modelira kot kompleksne medregionalne in časovne vzorce demske difuzije in širitve skozi menjave. Model pokaže, da ni preproste in izključujoče razlage, bodisi demske ali kulturne difuzije; v večini evrazijskih regij je bila na delu kombinacija demskih in kulturnih procesov.

KEY WORDS - cultural diffusion; demic diffusion; modelling; Neolithic; Eurasia

\section{Introduction}

The transition to agriculture and pastoralism, termed the 'Neolithic revolution' by Vere Gordon Childe (1925) fundamentally changed social systems and the relationship of people and their environments. However revolutionary - even termed 'traumatic' (Rowley-Conwy 2004) - this transition was locally, the more gradual it appears on the continental scale, spanning almost 10000 years of human prehistory and history (e.g., Barker 2006).

The spatial diffusion of the new agro-pastoral and animal husbandry innovations, technologies, and lifestyles played a major part in the abandonment of a foraging lifestyle following local innovations in only a few places worldwide that are associated with the domestication of plants and animals (Fuller et al. 2014). From these few founder regions, the new domesticates, knowledge of their cultivation and the idea of farming and herding itself spread to all but the most secluded or marginal regions of the world; not only did these cultural traits spread, but also the people who carried along their 'hitchhiking' traits (Ackland et al. 2007).
Consequently, the spatio-temporal pattern of dated Neolithic sites radiates outward from the founder regions. For different cultural and individual traits, the apparent rates of spreading can be determined (Edmonson 1961; Bocquet-Appel et al. 2012), but it is unclear from the spatio-temporal analysis of dated sites as to what process dominated the expansion (Lemmen et al. 2011). Within a broad spectrum of diffusion mechanisms that include, e.g., leapfrog migration and elite replacement (Zvelebil 1998) demic diffusion and cultural diffusion represent two contrasting views that have received widespread attention in the literature. The demic diffusion hypothesis suggests the introduction of the new agro-pastoral technologies through movements of people: migrations of any kind; the cultural diffusion hypothesis suggests a technology shift through indigenous adaptations and inventions fostered by culture contact: information dispersal of any kind.

Demic diffusion, i.e. the spread of agro-pastoralism by migration of people has been put forward as one of the earliest hypotheses for explaining the spatio- 
temporal pattern of Neolithic arrival dates in Europe (Clark 1965); evidence for demic diffusions is accumulating with modern mtDNA and Y-chromosomal analyses, revealing matrilineal and patrilineal relationships in space and time (Chikhi et al. 2002; Deguilloux et al. 2012; Fu et al. 2012) (although contrasting views have been presented by Vincenza Battaglia et al. (2008) and Wolfgang Haak et al. (2010)), and with earlier linguistic work (Renfrew, Level 1987).

Cultural diffusion is the spread of agro-pastoralism by information and material transmission in the absence of migrations. As both maternal and paternal genetic lines are continuous from the founder regions into Europe, approval for the cultural diffusion hypothesis depends on a temporal mismatch between the expansion of traits and knowledge and the expansion of people. Already Albert J. Ammerman and Luigi L. Cavalli-Sforza (1973) suggested that both demic and diffusive spread are active and that it is the relative contribution of each that needs to be investigated, rather than deciding on either demic or cultural diffusion. Furthermore, cultural diffusion theories have also been put forward as a reaction to processual diffusionist views and emphasise the agency and innovativeness of local populations (Hodder 1990) (but refuted again by e.g., Rowley-Conwy 2004).

Mathematical models on the spread of agro-pastoralism have a long tradition in Europe and can be traced back to Childe's (1925) observations on the spatio-temporal distribution gradient of ceramics from south-eastern to North-western Europe. This pattern was replicated from Neolithic radiocarbon dates by Grahame Clark (1965), and subsequently mathematically formulated by Ammerman and Cavalli-Sforza (1973) as the 'wave of advance' model on which many subsequent formulations have been built (Ackland et al. 2007; Galeta et al. 2011; Davison et al. 2009).

A common feature of diffusion models is concentric expansion from one or multiple centres of supposed origin, with modifications introduced to account for geographic bottlenecks, terrain, or rivers (Davison et al. 2006; Patterson et al. 2010; Silva, Steele 2014). Joaquim Fort $(2012 ; 2015)$ attempted to disentangle demic and cultural diffusion from both a modelling as well as a data perspective. In a diffusion model, he found that both demic and cultural diffusion are important, with demic diffusion responsible for $60 \%$ (vs. $40 \%$ for cultural) of the spreading process. Simi- larly, our own investigation (Lemmen et al. 2011) concluded that a mixed model produces a pattern of Neolithisation that best accords with the data.

Far fewer numerical studies have been performed for Eurasian regions outside Europe. The best investigated cases are probably South Asia and the Indian subcontinent. For this region Graeme J. Ackland et al. (2007) investigated the transition to agriculture as a diffusion process that emanates from a single founder region in Southwest Asia; in contrast, Mark A. Patterson et al. (2010) reported on a simulation of the Neolithic transition in India expanding from two centres, representing Chinese and $\mathrm{Ha}$ rappan migration streams. Our own simulations for the Indian subcontinent showed that the connection from the Indus region to the Levant was established only after the transition to agropastoralism (Lemmen, Khan 2012), consistent with the wheat/rice barrier identified by Graeme Barker (2006). The demic-cultural debate has not been investigated for greater Eurasia yet.

In the current study, I demonstrate with numerical simulations how the different assumptions about the diffusion process - interpreted as demic diffusion and cultural diffusion or a mixture thereof - may have played different roles in the spread of agropastoralism through Eurasia. Emanating from founder regions in North and South China, Central Asia, and the Levant about 9000 years ago, the entire continent (except Northern Eurasia) transitions to agropastoral life-styles by 3000 calBC, drawing a complex picture of cultural and demic diffusion.

The goal of this study is to investigate qualitatively the spatial and temporal predominance of either cultural or demic diffusion processes within Eurasia, and to provide a novel visualisation of the complexity of the interplay between these processes at a continental scale.

\section{Methods}

I employ the Global Land Use and technological Evolution Simulator (GLUES, Lemmen et al. 2011) - a numerical model of prehistoric innovation, demography, and subsistence economy - to hindcast the regional transitions to agropastoralism and the diffusion of people and innovations across Eurasia for the period 7500-3500 calBC.

The model operates on 294 (country-like) spatial units within the domain $-15^{\circ} \mathrm{E}$ to $135^{\circ} \mathrm{E}$ and $10^{\circ} \mathrm{N}$ 
to $60^{\circ} \mathrm{N}$ (Fig. 1). These regions represent ecozones that have been derived to represent homogenous net primary productivity (NPP) clusters based on a 3000 calBC $1^{\circ} \times 1^{\circ}$ palaeo-productivity estimate (Wirtz, Lemmen 2003); this estimate was derived from a dynamic palaeovegetation simulation (Brovkin et al. 1997) scaled down with the Mark New et al. (2001) climatology. By using NPP, many of the environmental factors taken into account by other expansion or predictive models, such as altitude, latitude, rainfall, or temperature (e.g., Silva et al. 2014b; Arıan 2014).

Within each region, a trait-based adaptive model describes regional societies with three characteristics: intrinsic innovations (technology), extrinsic (economic diversity), and subsistence style (Lemmen et al. 2011). The evolution of these characteristic traits is interdependent and drives the growth of a regional population according to the gradient adaptive dynamics approach formulated by Kai W. Wirtz and Bruno Eckhardt (1996) for ecological systems. In his approach, the rate of change of the mean of each characteristic trait is calculated as the product of the trait's variability and its marginal growth benefit, i.e. the derivative of population growth rate with respect to the trait, evaluated at the mean growth rate. In Kai W. Wirtz and Carsten Lemmen (2003), we adopted this mathematical approach for social systems; as the approach is an aggregate formulation operating on the statistical moments of traits and growth rate, it requires large populations, and thus larger geographic areas. For further details on the trait-based model formulation, see Lemmen, Detlef
Gronenborn, and Wirtz (2011) (their supplementary online material).

Exchange of characteristic traits and migration of people between regions is formulated with a diffusion-like approach, i.e. the flow of a quantity (technology, economic diversity, subsistence style) is directed from a region with higher influence (i.e. product of technology and population) to a region with lesser influence. The speed of the spread is proportional to the interregional difference of the respective quantity, and influence is proportional to the influential region's technology and proportional to common boundary length divided by interregional distance. Migration is furthermore dependent on acceptable living conditions (positive growth rate) in the influenced region. Equations for interregional interchange are given in the appendix. The size of the simulation regions (on average $300000 \mathrm{~km}^{2}$ ) is insufficient for detailed local analyses, but appropriate for sub-continental and continental-scale simulations and necessary to allow for parameter space exploration.

We performed three different simulations, one with mixed diffusion, one with exclusively demic diffusion and one with exclusively cultural diffusion (see appendix for the different formulations). The global simulations (in total 685 regions) start at 8500 calBC, assuming equal initial conditions for all societies in all regions; we use the same set of parameters used by Lemmen, Gronenborn and Wirtz (2011): for the three diffusion scenarios, we obtained the diffusion coefficients by tuning each model to opti-

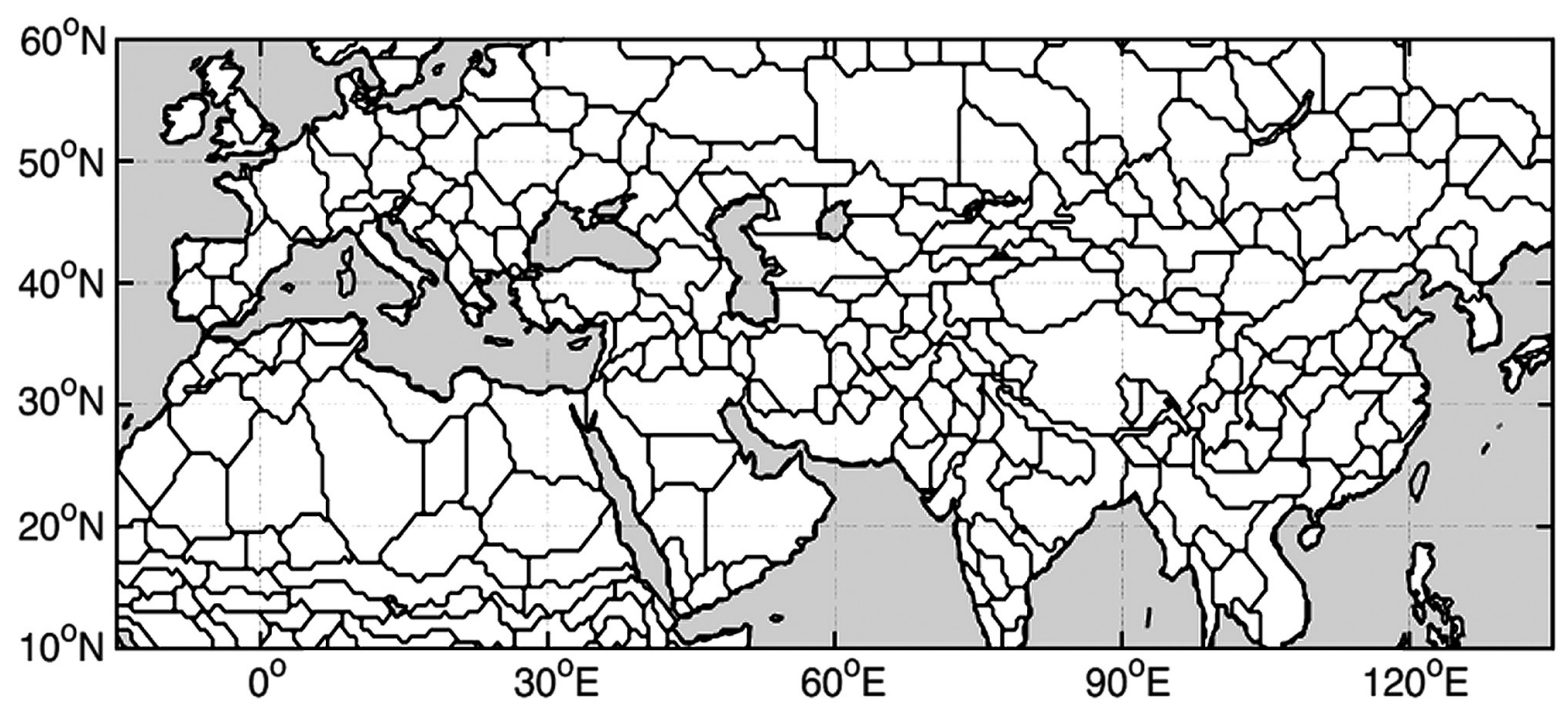

Fig. 1. Geographic setting of 294 Eurasian and North African simulation regions in the Global Land Use and technological Evolution Simulator. This is a subset of the full (global) simulation comprising 685 world regions. 
mally represent the European arrival dates. Simulations were performed with GLUES version 1.1.20a; this version can be obtained as free and open source from http://sf.net/p/glues

Despite tuning all scenarios to the radiocarbon record used in Lemmen, Gronenborn and Wirtz (2011), the highest correlation could only be obtained with the mixed (base) scenario. To disentangle cultural and demic diffusion processes, we compared the demic and cultural diffusion scenarios with each other after normalisation with the mixed scenario. Where the demic scenario predicted at least a $10 \%$ greater share of agro-pastoral life style, we diagnosed a predominantly demic diffusion. Where the cultural scenario predicted a greater share, we diagnosed a predominantly cultural diffusion. To estimate the overall influence of demic versus cultural diffusion, we averaged for each region the relative predominance of demic over cultural diffusion processes over time.

\section{Results}

The timing of the arrival of agro-pastoralism (Fig. 2) reveals its multicentric origin and spatio-temporal expansion, including the typical radiation from founder regions seen in all diffusive models.

By 6600 calBC, the transition to agro-pastoralism has occurred in five founder regions: (1) northern coastal China, (2) southern tropical inland China, (3) the Northern Indus region, (4) West Anatolia and Greece, and (5) the Zagros Mountains. At this time, emerging agro-pastoralism connects the Chinese regions with each other (Fig. 2). By 6300 calBC, agro-pastoralism is the dominant lifestyle in all founder regions; it has expanded west to the Balkans and Italy, and east to Korea. A broad band of agriculturalists is visible across China.

By 6100 calBC, the Levant and Anatolian founder regions connect and expand north and eastward, likewise the Chinese regions. The Indus regions extend towards the Ganges. These emerging life styles consolidate in the ensuing centuries. By $5500 \mathrm{calBC}$, the western Eurasian centre has continued to expand in all directions, reaching around the Black Sea and to the Caspian Sea. All of China has transitioned; emerging agro-pastoralism connects the Indus

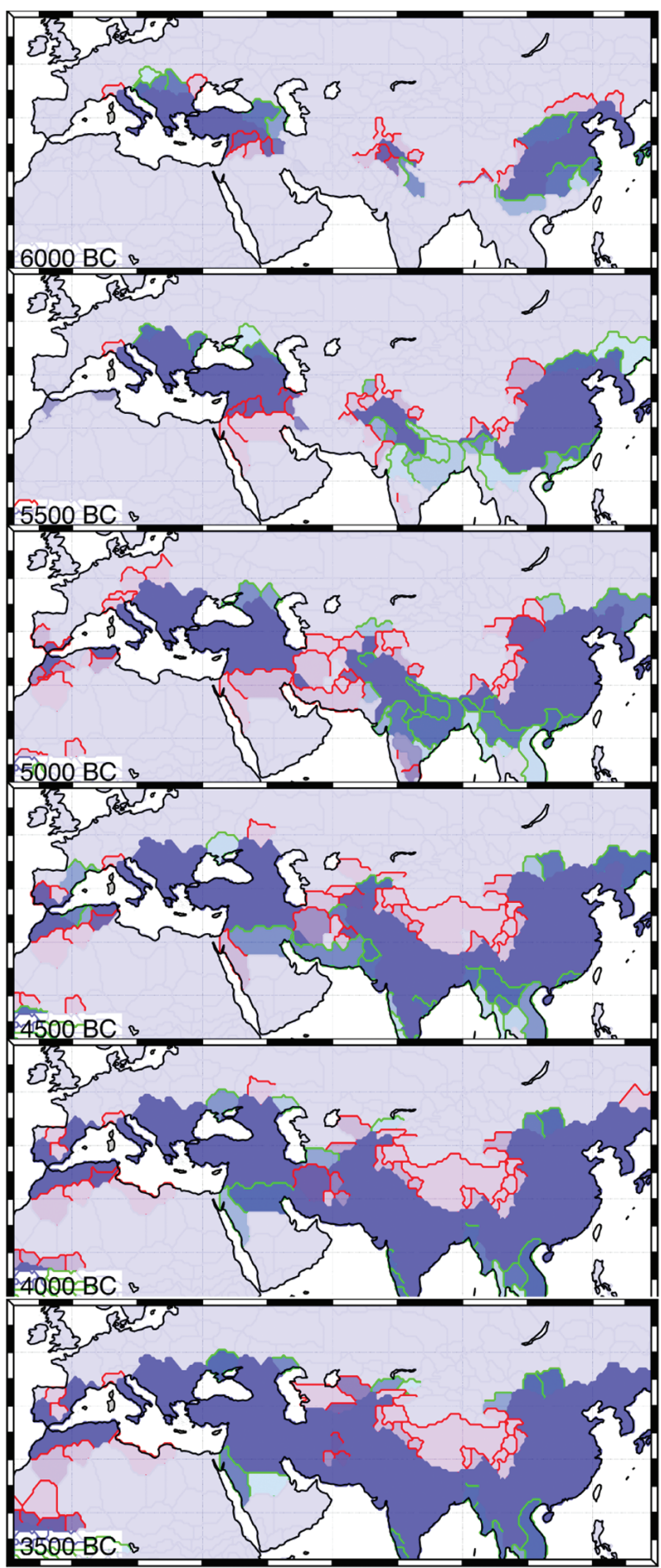

Borders with dominant

- demic diffusion

- A cultural diffusion

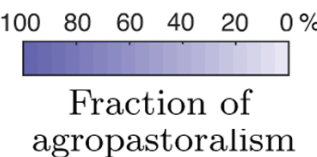

Fig. 2. Simulated transition to agriculture, 6000-3500 $B C$. The darker the shading, the higher the fraction of agropastoralists in the population. Red lines show regional borders with demic diffusion events, green lines show regional borders with cultural diffusion events. 
to the Chinese region. By 5100 calBC, North African pastoralism emerges. There is now one large Asian agropastoralist region, also with emergent transitions throughout India.

By 4700 calBC the Western and Eastern Eurasian centre connect. Agro-pastoralism emerges in Southeast Asia and Western Europe. By 4000 calBC, one large belt of agro-pastoral lifestyle connects the Mediterranean with West Asia, South Asia, and East Asia.

Multiple, intermittent, recurrent, and predominantly demic or cultural diffusion processes are seen throughout the simulation for all regions. For example, exchange processes around the Central Asian plateau are dominated by demic diffusion at all times. At most times, North African and Southwest European exchange processes are dominated by demic diffusion. Cultural diffusion, on the other hand, is at all times dominant within East and South China, and in Southeast Asia. For most of the time it is dominant on the Indian subcontinent.

A more complex pattern of demic and cultural diffusion in space and time is observed in Western Asia and Southeast Europe. Diffusion from the Fertile Crescent is predominantly demic before 4900 calBC, and cultural thereafter. Just east of the Red Sea, it is demic until 4200 calBC, and cultural from 4000 calBC. The expansion of Southeastern and Anatolian agro-pastoralism northward is predominantly cultural at 5500 calBC, and predominantly demic 500 years later. At 5000 calBC, it is demic west of the Black Sea and cultural east of the Black Sea. At 4500 calBC, demic processes again take over part of the eastern Black Sea northward expansion.

Integrated over time, both demic and diffusive processes are equally relevant for most regions. No region, however, shows a demic contribution of less than $30 \%$, and all regions have at least a cultural contribution of more than $15 \%$. Ninety per cent of all regions show no dominance of either demic or cultural diffusion (Fig. 3). A dominance of demic diffusion is evident in the Sahara, and the Hindu Kush and other regions around the Central Asian Plateau.
Cultural diffusion is persistent on the Arabian Peninsula, South and Southeast Asia, and several regions in southern Siberia and north of the Aral Sea.

\section{Discussion}

During each regional transition, both cultural and demic processes play a role, often even contribute sequentially to a regional agro-pastoral transition. In only very few regions, the simulated transition is best explained by either demic or cultural diffusion processes. Previous attempts to prove either demic or diffusion processes as solely responsible for regional agro-pastoral conditions seem too short-fetched, when the spatial and temporal interference of cultural and diffusive processes might have left a complex imprint on the genetic, linguistic and artefactual record.

In this respect, we confirm the suggestion of Ammerman and Cavalli-Sforza (1973) and Fort's analysis (2012) of a probably mixed process underlying the expansion of agropastoralism and herding. The new finding here is that for most regions within Eurasia, both processes were active, often contemporaneously, or subsequently, and that a time-integrated view
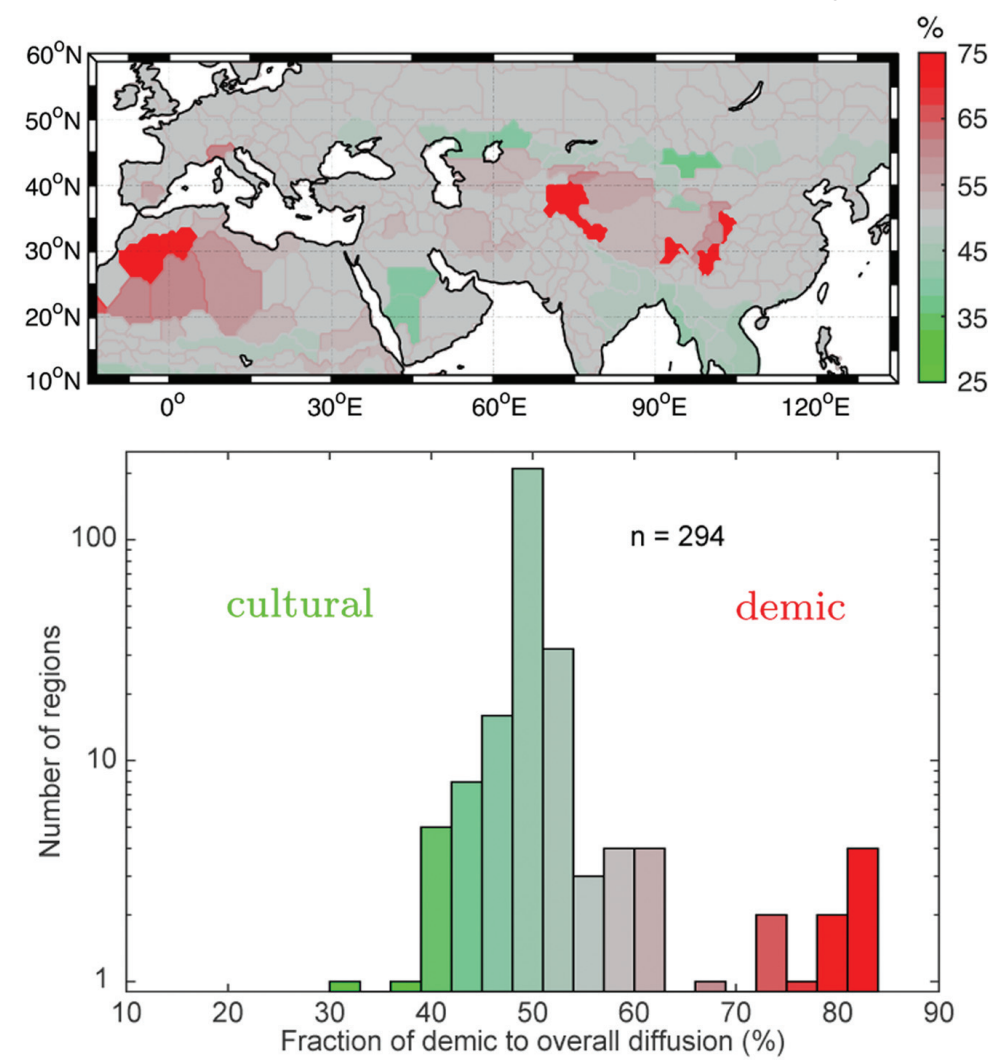

Fig. 3. Time integrated contribution of predominantly demic (red) and cultural (green) diffusion represented geographically (top panel) and as a histogram (bottom panel). For most regions, no predominance (grey) of either mechanism is found. 
(such as population genetic or linguistic analyses) only picks out the few regions where either process dominates. For most regions, however, all of the complex interplay between cultural and demic diffusion is hidden in a time-integrated view.

This time-integrated view is, however, the only information that is accessible from radiocarbon arrival date compilations and most model simulations. Fort (2015), e.g., analysed the variations in diffusion speeds and attributed these to predominant cultural, demic, or mixed diffusion for slow, intermediate, and fast apparent diffusion rates, respectively. Theirs and our analysis indicate potentially more demic exchange within Iberia and Northern Italy, separated by predominant cultural or mixed exchange in Southern France; at the coarse scale of the model regions, however, this comparison should not be expected to yield conclusive insights.

Based on this time-integrated view, ancient DNA work (e.g., Bramanti et al. 2009) infers a demic signal throughout Europe. As time control is difficult in this record, the demic signal might have occurred before the expansion of agro-pastoralists by migrations of Mesolithic hunter-gatherers or horticulturalists, or even later. The Y-chromosomal and the mitochondrial DNA data show different expansion patterns and can be attributed to multiple migration events, including pre-Neolithic and post-Neolithic demic events (Szécsényi-Nagy et al. 2014), although most of the introduced variability in the European gene pool was well established by the Bronze Age (Ricaut 2012).

Migration might have to be functionally disconnected from the spread of agro-pastoralism (Gronenborn 2011). Our simulations show that it was not necessarily only one migration wave and another cultural diffusion event that shaped the expansion of agropastoralism, but a multitude of combined events, sometimes more demic, sometimes more cultural, dominated. This two-faceted expansion process then explains both archaeogenetic data as well as cultural diffusion evidence, without requiring distinct migratory processes before the expansion of agro-pastoralism.

In GLUES, I did not consider maritime migration, because the Iberian arrival dates could largely be reconstructed without explicitly including this process in the model, as a secondary wave of advance enters Iberia from Gibraltar (there are land bridges connecting across the strait of Gibraltar, the Bosphorus and the English Channel to compensate for the lack of maritime transport), which possibly emulates the fast leap-frog maritime that has been proposed for that region (Battaglia et al. 2008). For the purpose of investigating intra-continental diffusion processes in a compact land mass like Eurasia, an additional coastal or sea-mediated spread is not required.

The diachronic view of exchange processes presented here may help to identify individual migration and cultural exchange processes better than a timeintegrated view. Thus, evidence of trade and exchange between two cultural layers with genetic continuity does not necessarily exclude demic diffusion during the entire period of interest, nor does a different genetic signal imply that cultural diffusion did not take place, or did not take place at other times.

Where do we see preferential cultural or demic diffusion in this study? Very roughly, mountainous regions seem to favour demic diffusion in the model simulation when integrated over time (Fig. 3). This is especially visible for the Central Asian plateau and its ridges. The Alps, the Pyrenees, the Iranian Plateau fit this pattern. Other important mountain regions, such as Anatolia or the Indian Ghats do not exhibit preferential demic diffusion.

Together with the apparent preferred demic diffusion in the western Sahara this possibly gives a hint that a lack of local adoption (due to environmental constraints) could be a reason for slower or lesser cultural diffusion. This does not explain, however, the preferential cultural diffusion in the (also environmentally marginal) Arabian Peninsula. Clearly, more work both in situ and in silico has to be done to explore the possibility of an environmental constraint selecting for a specific diffusion process.

These simulations were performed without being confronted with sufficient regional archaeological data for most parts of Eurasia, and the parameter values were tuned to best reproducing the origin locations and times of agro-pastoralism. Only European radiocarbon dates were used to estimate the diffusion coefficients for the demic, cultural and mixed diffusion scenarios (see appendix). One Eurasian region tested for model skill is the Indus region (Lemmen, Khan 2012), where the model appears slightly too fast compared to the (often very uncertain) dates; in a non-Eurasian study I found (Lemmen 2013) that radiocarbon dates for the transitory period 1000 BC-AD 1000 in Eastern North America were succes- 
sfully simulated, again with a small model bias towards earlier dates.

The overall simulation for Eurasia is thus realistic in the sense of providing a consistent spatio-temporal view of one expectation of prehistoric developments (from a Eurocentric view) at a large scale. The results are not real in the sense that they provide the exact historical trajectory that has been found at the local scale (comp. Ackland et al. 2007). The great challenge and promise arising from the simulation is thus to confront the expectation from the model with the realisation in the archaeological record: only when both disagree can we learn that either the model is not performing well enough, or that there is a process that is emancipated from the environmental and cultural context: then we have quantified human agency. The individual or societylevel decision to migrate or to communicate should be expected to be at least as rich and complex as the cultural-demic diffusion picture appearing from a simulation.

\section{Conclusion}

I presented a numerical simulation study on the diffusion processes during Neolithisation in Eurasia, using an adaptive model of prehistoric societies in their environmental context that is able to resolve local innovation, cultural diffusion and demic diffusion. Although a mixed diffusion process was already suggested long ago, the analysis of simulations with either cultural or demic diffusion, and with mixed diffusion reveals an even more complex spatio-temporal pattern of the expansion of agro-pastoralism throughout Eurasia than has previously been found: demic and cultural processes occur contemporaneously, or multiple times iteratively or intermittently in most regions of Eurasia. There is no simple demic or cultural explanation, but a very complex and rich interplay of both processes in time and space. The polarised debate of either demic or cultural diffusion should give way to acknowledging again this more complex picture and to studying and appreciating the richness of mechanisms.

\section{Appendix}

The diffusion process between a region $i$ and another region in its neighbourhood $j \in N$ is realized with three diffusion equations, representing communication, trade, and migration. Diffusion depends on the influence difference (Renfrew, Level 1979), where influence is defined as the product of population density $P$ and technology $T$. The diffusion flux $f$ is proportional to the influence difference relative to the average influence of regions $i, j$ times geographically determined conductance between the two regions.

The entries for $c_{i, j}$ in the conductance matrix $C$ between two regions $i, j$ are constructed from the common boundary length $L_{i, j}$ divided by the mean area of the regions $\sqrt{ }\left(A_{i} A_{j}\right)$. As in Jacob Etten and Robert Hijmans (2010), geographically not connected regions have zero conductance; to connect across the Strait of Gibraltar, the English Channel, and the Bosporus, the respective entries in $C$ were calculated as if a narrow land bridge connected them.

No additional account is made for increased connectivity along rivers (Davison et al. 2006; Silva, Steele 2014), as the regional setup of the model is biased (through the use of net primary productivity
(NPP) similarity clusters) toward elongating regions in the direction of rivers. Altitude and latitude effects are likewise implicitly accounted for by the NPP clustering in the region generation.

Finally, if the flux between $i, j$ is negative, it is directed inward from $j$ to $i$, else outward from $i$ to $j$.

$$
f_{i, j}=c_{i, j}\left(\frac{P_{i} T_{i} A_{i}+P_{j} T_{j} A_{j}}{A_{i}+A_{j}}-P_{j} T_{j}\right)
$$

Trade/information exchange: Trait value differences in all traits $X$ between $i$ and all its neighbours $j$ are summed and added to region $i$ 's trait value.

$$
\left.\frac{\mathrm{d} X_{i}}{\mathrm{~d} t}\right|_{\text {trade }}=\sigma_{\text {trade }} \sum_{j \in N_{i}, f_{i j}>0} f_{i j} \cdot\left(X_{j}-X_{i}\right)
$$

The parameter $\sigma_{\text {trade }}$ needs to be estimated (see below); trade is not mass-conserving.

Migration is composed of immigration or emigration, depending on the sign of the diffusion flux $f$.

$$
\left.\frac{\mathrm{d} P_{i}}{\mathrm{~d} t}\right|_{\text {demic }}=\sigma_{\text {demic }} \sum_{j \in N_{i}, f_{i j}>0} f_{i j} P_{j} \frac{A_{j}}{A_{i}}-\sum_{j \in N_{i}, f_{i j}<0} f_{i j} P_{i}
$$


The free parameter $\sigma_{\text {demic }}$ can be chosen to adjust the speed of migration (see below). Population is redistributed by scaling with region area $A$, thus, migration is mass-conserving.

Hitchhiking traits: Whenever people move in a demic process, they carry along their traits to the receiving region:

$$
\left.\frac{\mathrm{d} X_{i}}{\mathrm{~d} t}\right|_{\text {demic }}=\sigma_{\text {demic }} \sum_{j \in N_{i}, f_{i j}>0} f_{i j} X_{j} \frac{P_{j} A_{j}}{P_{i} A_{i}}
$$

\section{Spread parameter estimation}

Suitable values for the spread parameters are assessed after all other model parameters have been fixed (for the equations and parameters not directly relevant to the demic/diffusive analysis, see the supporting online material provided as a supplement to Lemmen, Gronenborn and Wirtz (2011)).

We initially assume that information travels two orders of magnitude faster than people, based on the typical size of exchange networks (1000km; Mauvilly et al. 2008; Gronenborn 1999), the average active life time of a tradesperson (order 10 years), and the comparison with the typical demic front speed of the order $1 \mathrm{~km}$ per year (Ammerman, Cavalli-Sfor$z a$ 1973). Starting with this fixed relation between $\sigma_{\text {trade }}$ and $\sigma_{\text {demic, }}$ we vary both parameters such that we get the highest correlation with the dataset by Ron Pinhasi, Joaquim Fort and Albert Ammerman (2005) on European sites; with $\sigma_{\text {trade }}=0.2$ and $\sigma_{\text {trade }}$ $=0.002$ the highest correlation achieved is $r^{2}=0.61$ $(n=631, p<0.01)$. Analysis of the simulation confirms that this is a parameterisation that describes mixed diffusion (Lemmen et al. 2011.Fig. O).

For a purely demic diffusion model, trade was switched off $\left(\sigma_{\text {trade }}=0\right)$ and $\sigma_{\text {demic }}$ was varied (systematically increased) to again obtain the best correlation with the data. The estimated parameter value is $\sigma_{\text {demic }}=0.008$. The respective procedure was applied to estimate the parameter $\sigma_{\text {trade }}$ for a purely cultural diffusion best-fitting model; its value was determined to be 0.3 .

\section{References}

Ackland G. J., Signitzer M., Stratford K. and Cohen M. H. 2007. Cultural Hitchhiking on the Wave of Advance of Beneficial Technologies. Proceedings of the National Academy of Sciences of the United States of America 104(21): 8714-8719.

Ammerman A. J., Cavalli-Sforza L. L. 1973. A Population Model for the Diffusion of Early Farming in Europe. In C. Renfrew (ed.), The Explanation of Culture Change: Models in Prehistory. Duckworth. London: 343-357.

Arıkan B. 2014. Macrophysical Climate Modelling, economy, and social organization in Early Bronze Age Anatolia. Journal of Archaeological Science 43: 38-54.

Barker G. 2006. The Agricultural Revolution in Prehistory: Why Did Foragers Become Farmers? Oxford University Press. Oxford.

Battaglia V., Fornario S., Al-Zahery N., Olivieri A., Underhill P. A. and Semino 0. 2008. Y-Chromosomal Evidence of the Cultural Diffusion of Agriculture in Southeast Europe. European Journal of Human Genetics 17(6): 820830.

Bocquet-Appel J.-P., Naji S., Vander Linden M. and Kozłowski J. 2012. Understanding the Rates of Expansion of the
Farming System in Europe. Journal of Archaeological Science 39(2): 531-546.

Bramanti B., Thomas M. G., Haak W., Unterlaender M., Jores P., Tambets K., Antanaitis-Jacobs I., Haidle M. N., Jankauskas R., Kind C.-J., Lueth F., Terberger T., Hiller J., Matsumura S., Forster P. and Burger J. 2009. Genetic Discontinuity Between Local Hunter-Gatherers and Central Europe's First Farmers. Science 326(5949): 137-140.

Brovkin V., Ganopolski A. and Svirezhev Y. 1997. A Continuous Climate-Vegetation Classification for Use in Climate-Biosphere Studies. Ecological Modelling 101(2-3): 251-261.

Chikhi L., Nichols R. A., Barbujani G. and Beaumont M. A. 2002. Y Genetic Data Support the Neolithic Demic Diffusion Model. Proceedings of the National Academy of Sciences of the United States of America 99(17): 1100811013.

Childe V. G. 1925. The Dawn of European Civilization. Routledge. London.

Clark J. G. D. 1965. Radiocarbon Dating and the Expansion of Farming Culture from the Near East over Europe. Proceedings of the Prehistoric Society 31: 57-73. 
Davison K., Dolukhanov P. M. and Sarson G. R. 2009. Multiple Sources of the European Neolithic: Mathematical Modelling Constrained by Radiocarbon Dates. Quaternary International 44: 1-17.

Davison K., Dolukhanov P. M., Sarson G. R. and Shukurov A. 2006. The Role of Waterways in the Spread of the Neolithic. Journal of Archaeological Science 33(5): 641652.

Deguilloux M.-F., Leahy R., Pemonge M.-H. and Rottier S. 2012. European Neolithization and Ancient DNA: An Assessment. Evolutionary Anthropology 21(1): 24-37.

Edmonson M. S. 1961. Neolithic Diffusion Rates. Current Anthropology 2(2): 71-102.

Etten J. van, Hijmans R. J. 2010. A Geospatial Modelling Approach Integrating Archaeobotany and Genetics to Trace the Origin and Dispersal of Domesticated Plants. PLoS One 5(8): e12060.

Fort J. 2012. Synthesis Between Demic and Cultural Diffusion in the Neolithic Transition in Europe. Proceedings of the National Academy of Sciences of the United States of America 109(46): 18669-18673.

2015. Demic and Cultural Diffusion Propagated the Neolithic Transition Across Different Regions of Europe. Journal of the Royal Society Interface 12: DOI: 10.1098/rsif.2015.0166.

Fu Q., Rudan P., Pääbo S. and Krause J. 2012. Complete Mitochondrial Genomes Reveal Neolithic Expansion into Europe. PLoS One 7(3): e32473.

Fuller D., Denham Q. T., Arroyo-Kalin M., Lucas L., Stevens C. J., Qin L. and Allaby R. G. 2014. Convergent Evolution and Parallelism in Plant Domestication Revealed by an Expanding Archaeological Record. Proceedings of the $\mathrm{Na}$ tional Academy of Sciences of the United States of America 111(17): 6147-6152.

Galeta P., Sládek V., Sosna D. and Bruzek J. 2011. Modelling Neolithic Dispersal in Central Europe: Demographic Implications. The American Journal of Physical Anthropology 146(1): 104-115.

Gronenborn D. 1999. A Variation on a Basic Theme: The Transition to Farming in Southern Central Europe. Journal of World Prehistory 13(2): 123-210.

2011. Neolithic Western Temperate and Central Europe. In M. Cummings, V. Jordan, P. Zvelebil (eds.), The Oxford Handbook of the Archaeology and Anthropology of Hunter-Gatherers. Oxford University Press. Oxford: $787-804$.
Haak W. and 18 co-authors 2010. Ancient DNA from European Early Neolithic Farmers Reveals Their Near Eastern Affinities. PLoS Biology 8(11): e1000536.

Hodder I. 1990. The Domestication of Europe. Structure and Contingency in Neolithic Societies. Blackwell. Oxford.

Lemmen C. 2013. Mechanisms Shaping the Transition to Farming in Europe and the North American Woodland. Archaeology, Ethnology and Anthropology of Eurasia 41(3): 48-58.

Lemmen C., Khan A. 2012. A Simulation of the Neolithic Transition in the Indus Valley. In L. Giosan, D. Q. Fuller, K. Nicoll, R. K. Flad and P. D. Clift. (eds.), Climate, Landscapes, Civilizations. Geophysical Monograph Series. American Geophysical Union. Washington: 107-114.

Lemmen C., Gronenborn D. and Wirtz K. W. 2011. A Simulation of the Neolithic Transition in Western Eurasia. Journal of Archaeological Science 38(12): 3459-3470.

Mauvilly M., Jeunesse C. and Doppler T. 2008. Ein Tonstempel Aus Der Spätmesolithischen Fundstelle von Arconciel/La Souche (Kanton Freiburg, Schweiz). Quartär 55: $151-157$

New M., Todd M. C., Hulme M. and Jones P. 2001. Precipitation Measurements and Trends in the Twentieth Century. International Journal of Climatology 21: 18991922.

Patterson M. A., Sarson G. R., Sarson H. C. and Shukurov A. 2010. Modelling the Neolithic Transition in a Heterogeneous Environment. Journal of Archaeological Science 37(11): 2929-2937.

Pinhasi R., Fort J. and Ammerman A. J. 2005. Tracing the Origin and Spread of Agriculture in Europe. PLOS Biology 3(12): $e 410$.

Renfrew C., Level E. V. 1979. Exploring Dominance: Predicting Polities from Centers. In C. Renfrew, K. Cooke (eds.), Transformations. Mathematical Approaches to Culture Change. Academic Press. New York: 145-166.

Renfrew C. 1987. Archaeology and Language. The Puzzle of Indo-European Origins. Cambridge University Press. Cambridge.

Ricaut F.-X. 2012. A Time Series of Prehistoric Mitochondrial DNA Reveals Western European Genetic Diversity Was Largely Established by the Bronze Age. Advances in Anthropology 2(1): 14-23.

Rowley-Conwy P. 2004. How the West Was Lost. Current Anthropology 45(S4): 83-113. 
Silva F., Steele J. 2014. New Methods for Reconstructing Geographical Effects on Dispersal Rates and Routes from Large-Scale Radiocarbon Databases. Journal of Archaeological Science 52: 609-620.

Szécsényi-Nagy A. and 30 co-authors 2014. Tracing the Genetic Orgigin of Europe's First Farmers Reveals Insights into Their Social Structure. BioRxiv: doi: http://dx.doi. org/10.1101/008664

Wirtz K. W., Eckhardt B. 1996. Effective Variables in Ecosystem Models with an Application to Phytoplankton Succession. Ecological Modelling 92(1): 33-53.
Wirtz K. W., Lemmen C. 2003. A Global Dynamic Model for the Neolithic Transition. Climatic Change 59(3): 333-367.

Zvelebil M. 1998. What's in a Name: The Mesolithic, the Neolithic, and Social Change at the Mesolithic-Neolithic Transition. In M. Edmonds, C. Richards (eds.), Understanding the Neolithic of north-western Europe. Cruithne Press. Glasgow: 1-36. 